\title{
X-ray Absorption Fine Structures of Uranyl(V) Complexes in a Nonaqueous Solution
}

\section{Koichiro TAKAO}

\begin{abstract}
The structures of three different $\mathrm{U}^{\mathrm{V}}$ complexes, $\left[\mathrm{U}^{\mathrm{V}} \mathrm{O}_{2} \text { (salophen)DMSO }\right]^{-}$, $\left[\mathrm{U}^{\mathrm{V}} \mathrm{O}_{2}(\mathrm{dbm})_{2} \mathrm{DMSO}\right]^{-}$, and $\left[\mathrm{U}^{\mathrm{V}} \mathrm{O}_{2} \text { (saldien) }\right]^{-}$, in a dimethyl sulfoxide (DMSO) solution were determined by X-ray absorption fine structure for the first time.
\end{abstract}

Keywords : Uranyl(V) Complex, X-ray Absorption Fine Structure, Structure Determination

(Received September 21, 2011)

\section{Introduction.}

Actinide elements at oxidation states +5 and +6 form actinyl ions $\left(\mathrm{AnO}_{2}{ }^{n+}, \mathrm{An}=\mathrm{U}, \mathrm{Np}, \mathrm{Pu}, \mathrm{Am}, n=1,2\right)$ with typical trans-dioxo arrangement. Among them, $\mathrm{U}(\mathrm{V})$ is quite unstable in solutions due to disproportionation. Recently, the chemistry of $U(V)$ is attracting special interests, because this field of actinides had so far poorly been explored. ${ }^{1)}$ Uranyl(V) carbonate, $\mathrm{U}^{\mathrm{V}} \mathrm{O}_{2}\left(\mathrm{CO}_{3}\right)_{3}{ }^{5-}$, is currently the only known stable U(V) species in aqueous solution. ${ }^{2)}$ Other stable $\mathrm{U}(\mathrm{V})$ was reported only in molten chloride salts at $600-750^{\circ} \mathrm{C}^{3)}$ We have previously found two stable $\mathrm{U}(\mathrm{V})$ complexes in nonaqueous systems, $\left[\mathrm{U}^{\mathrm{V}} \mathrm{O}_{2} \text { (salophen)DMSO }\right]^{-} \quad\left(\mathbf{1}^{\mathrm{V}}\right) \quad$ and $\left[\mathrm{U}^{\mathrm{V}} \mathrm{O}_{2}(\mathrm{dbm})_{2} \mathrm{DMSO}\right]^{-}\left(\mathbf{2}^{\mathrm{V}}\right)$ in DMSO (Chart 1). ${ }^{4) \mathrm{a}-\mathrm{d}}$ Several U(V) complexes have also been reported by other groups. ${ }^{4)-n}$ Most recently, we found a new stable $\mathrm{U}(\mathrm{V})$ complex in nonaqueous solution, $\left[\mathrm{U}^{\mathrm{V}} \mathrm{O}_{2} \text { (saldien) }\right]^{-}$in $\operatorname{DMSO}\left(\mathbf{3}^{\mathrm{V}}\right.$, Chart 1$){ }^{5)}$

The molecular structure of $\mathrm{U}(\mathrm{V})$ species represents an essential chemical aspect. For solid U(V) compounds, the structure determination is easily doable by single crystal XRD. This technique provides precise structural data, and in fact most of the structural characterizations of crystalline $U(V)$ species have been done this way. ${ }^{4 \mathrm{e}-\mathrm{m}}$ A structure in solid state is, however, not necessarily representative for that in solution, while single crystal XRD is not applicable to solution species. Infrared $^{4) b, c}$ and $\mathrm{NMR}^{4) \mathrm{h}-\mathrm{m}}$ spectroscopic methods were used in the previous studies on $\mathrm{U}(\mathrm{V})$ solution species. However, these methods provide only qualitative

理工学部助教（k.takao@st.seikei.ac.jp） evidence (e.g., vibration, ligand coordination, molecular symmetry, molecular weight estimated from diffusion coefficient), but do not provide quantitative structures such as bond distances. Furthermore, any information on solvent coordination (e.g., DMSO of $\mathbf{1}^{\mathbf{V}}$ and $\mathbf{2}^{\mathbf{v}}$ ) cannot be obtained because of strong absorption and/or rapid chemical exchange of the solvent. The most promising technique to overcome this problem is X-ray Absorption Fine Structure (XAFS) spectroscopy. The absorption edge is a good indicator of the oxidation state, and extended XAFS (EXAFS) can be transformed to a one-dimensional radial distribution function providing coordination numbers $(N)$ and interatomic distances $(R)$ of atoms around $U$ regardless of sample forms (e.g., crystalline, amorphous, and solution). In practice, the structures of $\mathrm{U}^{\mathrm{V}} \mathrm{O}_{2}\left(\mathrm{CO}_{3}\right)_{3}{ }^{5-}$ and $\mathrm{U}^{\mathrm{VI}} \mathrm{O}_{2}\left(\mathrm{CO}_{3}\right)_{3}{ }^{4-}$ in aqueous solution have been

Chart 1

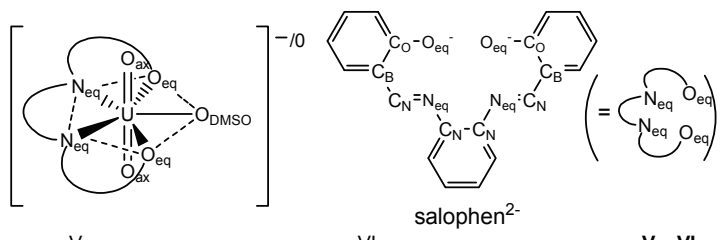

$\left[\mathrm{U}^{\vee} \mathrm{O}_{2}\right.$ (salophen)DMSO] $/ \mathrm{U}^{\mathrm{VI}} \mathrm{O}_{2}$ (salophen)DMSO $\left(1^{\mathrm{V} / 1} \mathrm{Vl}\right)$

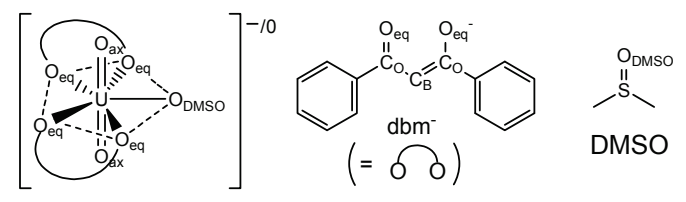

$\left[\mathrm{U}^{\vee} \mathrm{O}_{2}(\mathrm{dbm})_{2} \mathrm{DMSO}\right]^{-} / \mathrm{U}^{\mathrm{Vl}} \mathrm{O}_{2}(\mathrm{dbm})_{2} \mathrm{DMSO}\left(\mathbf{2}^{\mathrm{V}} / \mathbf{2}^{\mathrm{Vl}}\right)$

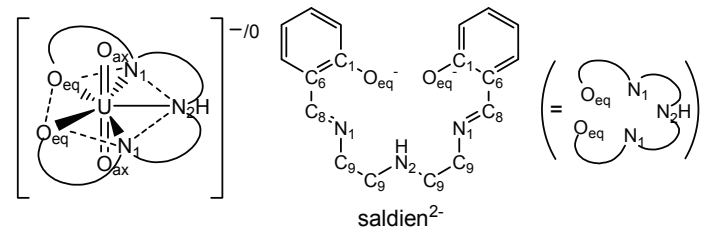

$\left[\mathrm{U}^{\vee} \mathrm{O}_{2} \text { (saldien) }\right]^{-} / \mathrm{U}^{\mathrm{V} \mathrm{I}} \mathrm{O}_{2}$ (saldien) $\left(3^{\mathrm{V} / 3^{\mathrm{V}}}\right)$ 
investigated by using XAFS. ${ }^{2 f, g}$ In this communication, we report the XAFS spectra and the structures of the $\mathrm{U}(\mathrm{V})$ complexes $\left(\mathbf{1}^{\mathbf{v}}, \mathbf{2}^{\mathbf{v}}\right.$, and $\left.\mathbf{3}^{\mathbf{v}}\right)$ in DMSO for the first time. The corresponding $\mathrm{U}(\mathrm{VI})$ species $\left(\mathbf{1}^{\mathbf{V I}} \mathbf{2}^{\mathbf{V I}}\right.$ and $\left.\mathbf{3}^{\mathbf{V I}}\right)$ were also studied, and the difference between $\mathrm{U}(\mathrm{V})$ and $\mathrm{U}(\mathrm{VI})$ is discussed.

\section{Experimental.}

Uranyl(VI) complexes, $\mathrm{U}^{\mathrm{VI}} \mathrm{O}_{2}$ (salophen)DMSO $\left(\mathbf{1}^{\mathrm{VI}}\right)$, $\mathrm{U}^{\mathrm{VI}} \mathrm{O}_{2}(\mathrm{dbm})_{2} \mathrm{DMSO}\left(\mathbf{2}^{\mathrm{VI}}\right.$ ) and $\mathrm{U}^{\mathrm{VI}} \mathrm{O}_{2}$ (saldien). DMSO $\left(3^{\mathrm{VI}}\right)$ as starting materials of the uranyl $(\mathrm{V})$ complexes were prepared by the method described in our previous articles. $^{\text {4a-d }}$ A sample solution of each uranyl(VI) complex in DMSO was prepared, and electrolyzed galvanostatically on a Pt wire working electrode (WE) at 0.5 or $1.0 \mathrm{~mA}$. Tetrabutylammonium perchlorate (TBAP) and 2-propanol were used as a supporting electrolyte $(0.30 \mathrm{M})$ and a sacrificial substance for electrolysis, respectively. 2-Propanol $\left(\begin{array}{lll}2.0 & \mathrm{M}\end{array}\right)$ was added only into the blank solution in a compartment for the counter (CE, Pt mesh) and reference electrodes (RE, $\mathrm{Ag} / \mathrm{AgCl}, 3 \mathrm{M} \mathrm{NaCl}$ ). The compartment for $\mathrm{WE}$ was connected to that for $\mathrm{CE}$ and $\mathrm{RE}$ through a porous glass tip filled with the blank solution without 2-propanol. During the electrolysis, the $\mathrm{N}_{2}$ gas was passed through the sample solution to remove dissolved oxygen and to convect the solution. Completion of the electrolysis was confirmed spectrophotometrically (Figure 1). ${ }^{4) d, 5)}$ After the electrolysis, the sample solution was immediately transferred to a PS/PMMA cuvette tightly sealed with silicone rubber top and hot melting glue. Concentrations of $\mathbf{1}^{\mathbf{v}}, \mathbf{2}^{\mathbf{v}}$ and $\mathbf{3}^{\mathbf{v}}$ in the sample solutions were 36, 33 and $31 \mathrm{mM}$, respectively. Color of each $\mathrm{U}(\mathrm{V})$ solution was green or dark-green. All operations of the $U(V)$ sample preparation were performed under dry $\mathrm{N}_{2}$ atmosphere in a dedicated glove box. The DMSO solution samples of the corresponding U(VI) complexes for XAFS measurements were also prepared.

X-ray absorption fine structure (XAFS) spectroscopy experiments were performed at the Rossendorf Beamline (ROBL) BM20 at the European Synchrotron Radiation Facility (6 GeV; 70-90 mA). ${ }^{7)}$ A Si(111) double-crystal monochromator was employed in
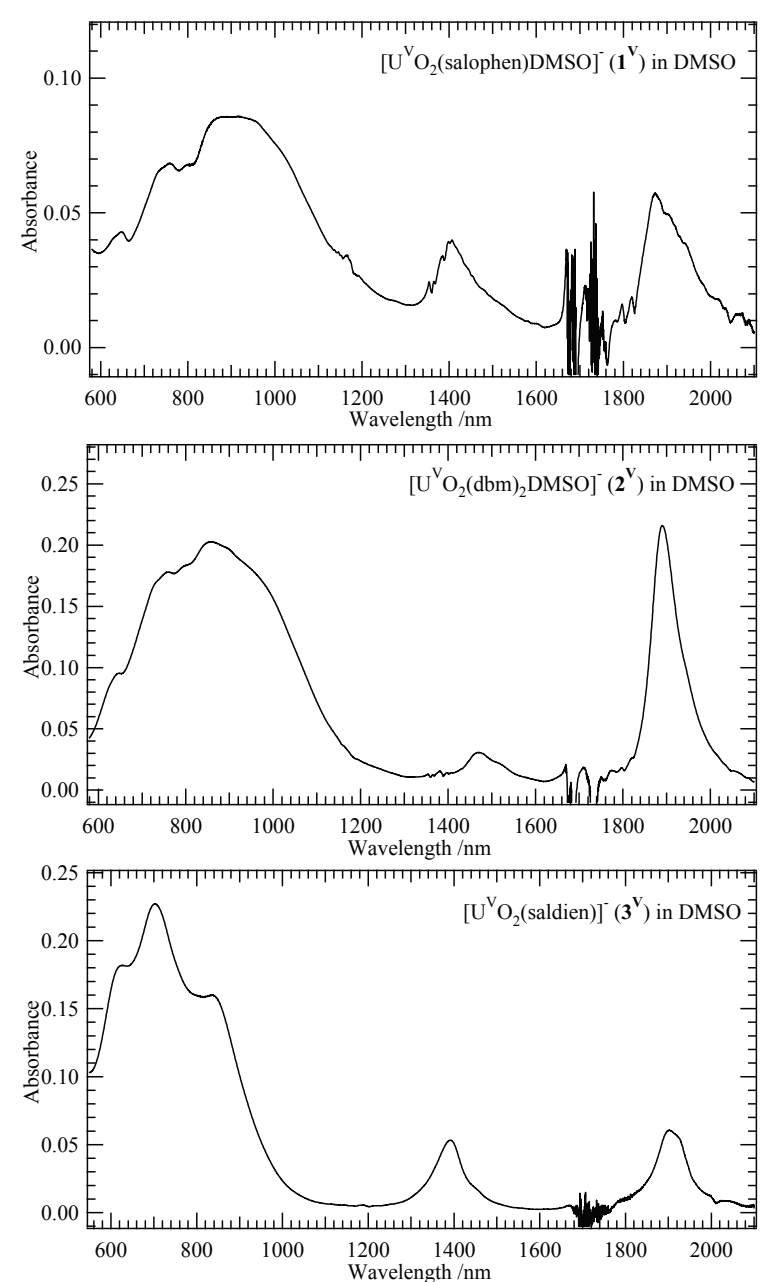

Figure 1. Visible-NIR absorption spectra of

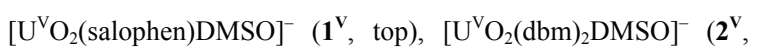
middle) and $\left[\mathrm{U}^{\mathrm{v}} \mathrm{O}_{2} \text { (saldien) }\right]^{-}\left(\mathbf{3}^{\mathrm{v}}\right.$, bottom), in DMSO. Noise around $1700 \mathrm{~nm}$ arises from strong absorption of the solvent DMSO.

channel-cut mode to monochromatize a white X-ray from the synchrotron. Uranium $\mathrm{L}_{\mathrm{III}}$-edge $\mathrm{X}$-ray absorption spectra of the $\mathrm{U}(\mathrm{V})$ and $\mathrm{U}(\mathrm{VI})$ samples were recorded in transmission mode by using Ar-filled ionization chambers at ambient temperature $\left(23 \pm 1^{\circ} \mathrm{C}\right)$ and pressure. The X-ray energy in each experimental run was calibrated by $\mathrm{Y}$ foil (fist inflection point at $17038 \mathrm{eV}$ ). The threshold energy, $E_{\mathrm{k}=0}$, of $\mathrm{U} \mathrm{L}_{\mathrm{III}}$-edge was defined at $17185 \mathrm{eV}$, regardless of $\mathrm{U}$ oxidation states. The X-ray absorption spectrum of each sample was accumulated twice and merged. The obtained spectra were processed using WinXAS ${ }^{8)}$ and IFEFFIT. ${ }^{9)}$ The EXAFS curve fit was performed in the $R$ space, using phases and amplitude calculated by FEFF $8.20{ }^{10}{ }^{10}$ Single-scattering paths from coordinating oxygen and nitrogen, surrounding carbon, and sulfur atoms (if 
necessary) and multiple-scattering paths from the linear uranyl ion were included in the EXAFS curve fit (Chart 1). The molecular structures of $\mathbf{1}^{\mathrm{VI}}$, $\mathrm{U}^{\mathrm{VI}} \mathrm{O}_{2}(\mathrm{dbm})_{2}$ (ethanol) (analogue of $\mathbf{2}^{\mathrm{VI}}$ ) and $\mathbf{3}^{\mathrm{VI}}$ from single crystal $\mathrm{X}$-ray analysis were used as initial structure models for $\mathbf{1}^{\mathrm{V}} / \mathbf{1}^{\mathrm{VI}}, \mathbf{2}^{\mathrm{V}} / \mathbf{2}^{\mathrm{VI}}$ and $3^{\mathrm{V}} / \mathbf{3}^{\mathrm{VI}}$, respectively. ${ }^{4 c, d}$ The amplitude decay factor, $S_{0}{ }^{2}$, was fixed at 0.9 , and the shifts in the threshold energy, $\Delta E_{0}$, were constrained to be the same value for all shells.

\section{Results and Discussion.}

Uranium $\mathrm{L}_{\mathrm{III}}$-edge XANES spectra of $\mathbf{1}^{\mathrm{V}} / \mathbf{1}^{\mathrm{VI}} \mathbf{2}^{\mathrm{V} / \mathbf{2}^{\mathrm{VI}}}$ and $3^{\mathrm{V}} / \mathbf{3}^{\mathrm{VI}}$ in DMSO are shown in Figure 2. The absorption edges of the U(VI) complexes are $17172.5 \mathrm{eV}$ for $\mathbf{1}^{\mathrm{VI}}$, $17172.9 \mathrm{eV}$ for $\mathbf{2}^{\mathrm{VI}}$ and $17172.6 \mathrm{eV}$ for $\mathbf{3}^{\mathrm{VI}}$, whereas those of $\mathbf{1}^{\mathbf{V}}, \mathbf{2}^{\mathbf{V}}$ and $\mathbf{3}^{\mathbf{V}}$ are 17171.3, 17171.1 and $17170.5 \mathrm{eV}$, respectively. These $\mathrm{U} \mathrm{L}_{\mathrm{III}}$-edges of the $\mathrm{U}(\mathrm{V})$ and $\mathrm{U}(\mathrm{VI})$ species are comparable with those of $\mathrm{U}^{\mathrm{V}} \mathrm{O}_{2}\left(\mathrm{CO}_{3}\right)_{3}{ }^{5-} \quad(17171.1 \mathrm{eV})$ and $\mathrm{U}^{\mathrm{VI}} \mathrm{O}_{2}\left(\mathrm{CO}_{3}\right)_{3}{ }^{4-}$ $(17173.3 \mathrm{eV}){ }^{2) g}$ The shift of the absorption edge by ca. 1-2 eV towards lower energy arises from the lower effective charge of $\mathrm{U}$ in $\mathrm{U}(\mathrm{V})$ than that in $\mathrm{U}(\mathrm{VI})$. After the white line, the characteristic XANES oscillation due to the multiple scattering along the linear uranyl unit was observed in both $\mathrm{U}(\mathrm{V})$ and $\mathrm{U}(\mathrm{VI})$ of each pair, indicating the presence of $\mathrm{UO}_{2}{ }^{n+}$. 2)g,11)

The $k^{3}$-weighted EXAFS spectra of $\mathbf{1}^{\mathrm{V}}, \mathbf{1}^{\mathrm{VI}}, \mathbf{2}^{\mathbf{v}}, \mathbf{2}^{\mathrm{VI}}$, $\mathbf{3}^{\mathbf{V}}$ and $\mathbf{3}^{\mathrm{VI}}$ in DMSO and their Fourier transforms (FTs) are shown in Figure 3. After the reduction from U(VI) to $U(V)$, spectral changes were observed in both amplitude and frequency of the EXAFS oscillation,

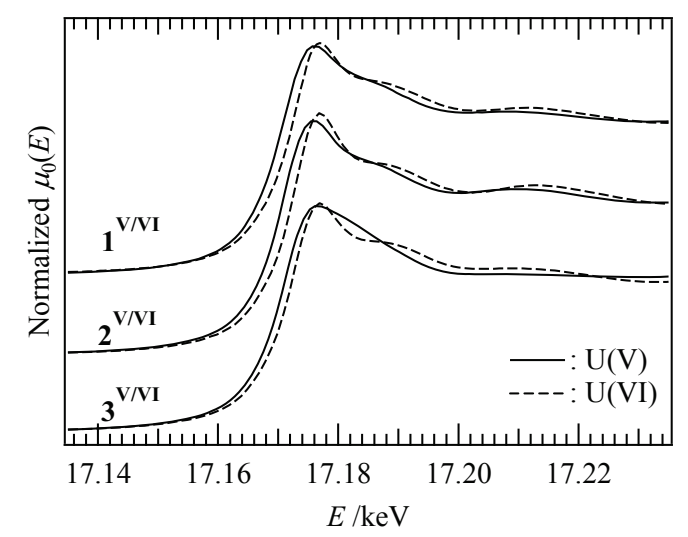

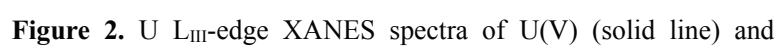
$\mathrm{U}(\mathrm{VI})$ (dashed line) complexes in DMSO. indicating structural modification around U. Several EXAFS spectra $\left(\mathbf{1}^{\mathbf{V}}, \mathbf{1}^{\mathbf{V I}}, \mathbf{3}^{\mathrm{V}}\right.$ and $\left.\mathbf{3}^{\mathrm{VI}}\right)$ show the characteristic peak at ca. $10.5 \AA^{-1}$ attributable to $2 \mathrm{p} 4 \mathrm{f}$ double-electron excitation. ${ }^{12)}$ If a $\mathrm{U}(\mathrm{V})$ cation-cation complex is formed, a peak due to the $\mathrm{U} \cdots \mathrm{U}$ interaction (ca. 3.5 and $4.3 \AA$ ) would be observable in the FT. In Figure 3, all the three different $U(V)$ complexes do not show remarkable peaks correlated to such an $\mathrm{U} \cdots \mathrm{U}$ interactions. This suggests that the $\mathrm{U}(\mathrm{V})$ complexes are present as mononuclear species. From the viewpoint of the molecular weight calculated by diffusion coefficient, Nocton et al. already proposed that $\mathbf{2}^{\mathbf{V}}$ keeps its monomeric structure in DMSO. ${ }^{4 \mathrm{i}}$ Their proposition was corroborated by our EXAFS study.

To determine the structures of the U(V) and U(VI) complexes in the DMSO solutions, EXAFS curve fits were performed. The estimated structural parameters of all complexes are summarized in Table 1 together with the mean interatomic distances in the crystalline $\mathrm{U}(\mathrm{VI})$ complexes $\left(R_{\text {cryst }}\right)^{5), 6), 13)}$ The calculated quantities, $N$ and $R$, in this table well reproduce the experimental EXAFS spectra and FTs as shown in Figure 3, and are
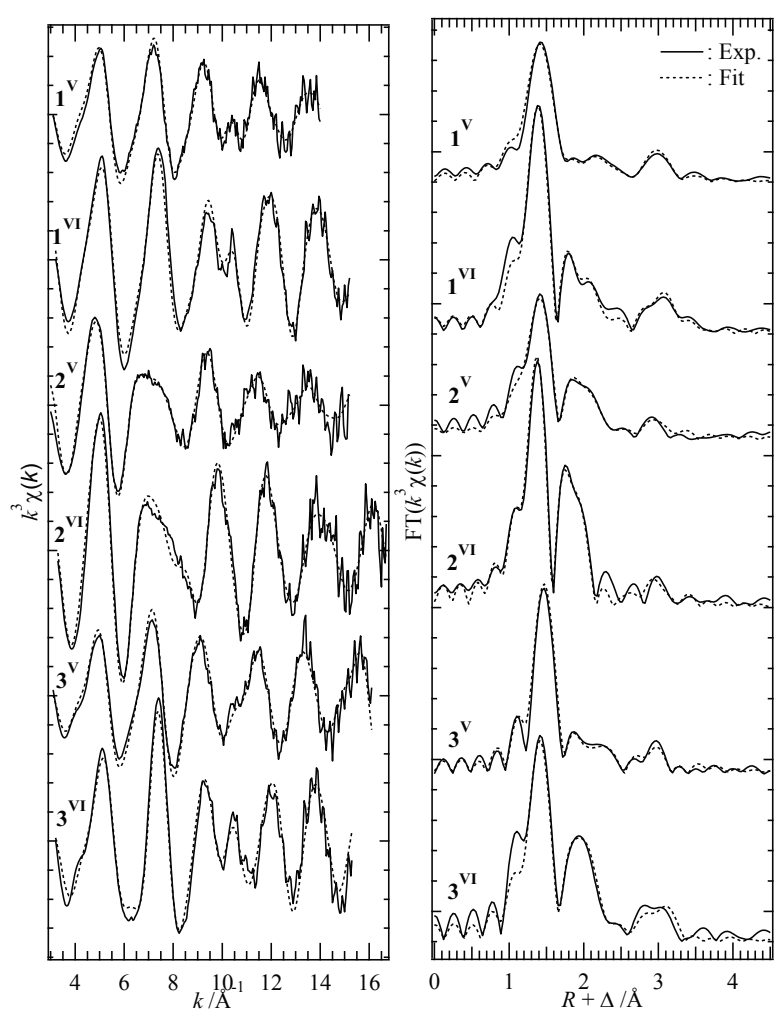

Figure 3. $k^{3}$-weighted $\mathrm{U} \mathrm{L}_{\mathrm{III}}$-edge EXAFS spectra (left) and their Fourier transforms (right) of U(V) and U(VI) complexes in DMSO together with the best fit lines from EXAFS curve fits. 
in line with those of the corresponding U(VI) species in solid state.

The $\mathrm{U}-\mathrm{O}_{\mathrm{ax}}$ distances of $\mathbf{1}^{\mathbf{V}}$ and $\mathbf{1}^{\mathbf{V I}}$ are 1.84 and 1.80 $\AA$, respectively. The difference between the two distances $\left(\Delta R\left(\mathrm{U}-\mathrm{O}_{\mathrm{ax}}\right)\right)$ is $0.04 \AA$, which is consistent with our previous estimation from IR spectroscopy. ${ }^{4) c}$ In the equatorial plane, the distances between $U$ and the coordinating atoms of salophen ${ }^{2-}$ in $\mathbf{1}^{\mathbf{V}}$ are slightly longer than those in $\mathbf{1}^{\mathrm{VI}}$ by $0.04-0.06 \AA$. It must be emphasized that the $\mathrm{U}-\mathrm{O}_{\mathrm{DMSO}}$ distance in $\mathbf{1}^{\mathbf{V}}$ is unexpectedly long $(2.91 \AA)$, while that in $\mathbf{1}^{\text {VI }}(2.38 \AA)$ is almost same as in the solid state. Since such a long distance between $\mathrm{U}$ and $\mathrm{O}_{\mathrm{DMSO}}$ seems to be unusual for the uranyl complex, validities of $R\left(\mathrm{U}-\mathrm{O}_{\mathrm{DMSO}}\right)$ estimation and the EXAFS curve fit need to be examined. The second system, $\mathbf{2}^{\mathrm{V}} / \mathbf{2}^{\mathrm{VI}}$, also involves the DMSO coordination. Therefore, the comparison between $\mathbf{1}^{\mathrm{V}}$ and $\mathbf{2}^{\mathrm{V}}$ is suitable for this subject. The structural parameters of both $2^{\mathbf{V}}$ and $\mathbf{2}^{\mathbf{V I}}$ show the similar trends with the $\mathbf{1}^{\mathrm{V}} / \mathbf{1}^{\mathrm{VI}}$ system, i.e., $R\left(\mathrm{U}-\mathrm{O}_{\mathrm{ax}}\right)=$ $1.85 \AA$ for $2^{\mathrm{V}}, 1.78 \AA$ for $\mathbf{2}^{\mathrm{VI}}, \Delta R\left(\mathrm{U}-\mathrm{O}_{\mathrm{ax}}\right)=0.07 \AA$ in agreement with IR result, ${ }^{4) c}$ and lengthening of $R\left(\mathrm{U}-\mathrm{O}_{\mathrm{eq}}\right)$ by the reduction. The quantity of interest here, $R\left(\mathrm{U}-\mathrm{O}_{\text {DMSO }}\right)$ in $\mathbf{2}^{\mathbf{V}}$, is estimated as $2.89 \AA$, which is similar to that in $\mathbf{1}^{\mathbf{V}}$. Thus, it is highly probable that the long $R\left(\mathrm{U}-\mathrm{O}_{\mathrm{DMSO}}\right)$ around $2.9 \AA$ is present in both $\mathbf{1}^{\mathbf{V}}$ and $2^{\mathrm{V}}$. $R\left(\mathrm{U}-\mathrm{O}_{\mathrm{DMSO}}\right)$ in the $\mathrm{U}(\mathrm{V})$ complexes is still shorter than the sum of van der Waals radii of $\mathrm{U}$ and $\mathrm{O}$ $\left.(1.86+1.52=3.38 \AA),{ }^{14}\right)$ indicating that such a long bond formation is feasible. $R(\mathrm{U} \cdots \mathrm{S})$ in $\mathrm{U}(\mathrm{V})$ is not very different from that of U(VI) in both couples. This arises from flexibility of the $\mathrm{U}-\mathrm{O}-\mathrm{S}$ bond angle.

In the system of $3^{\mathrm{V}} / 3^{\mathrm{VI}}$, where the unidentate ligand is no longer included, the stronger equatorial coordination due to the pentadentate saldien $^{2-}$ is expected. The structural data concerning the $\mathrm{U}-\mathrm{O}_{\mathrm{ax}}$ bond are similar to the former two systems; $R\left(\mathrm{U}-\mathrm{O}_{\mathrm{ax}}\right)=$ $1.86 \AA$ for $3^{\mathrm{V}}, 1.81 \AA$ for $\mathbf{3}^{\mathrm{VI}}$, and $\Delta R\left(\mathrm{U}-\mathrm{O}_{\mathrm{ax}}\right)=0.05$ $\AA{ }^{4) \mathrm{c}}$ In contrast, very slight differences (within $0.01 \AA$ ) in the equatorial coordination were found between $3^{\mathbf{V}}$ and $3^{\mathrm{VI}}$, except for a significant shortening of $R\left(\mathrm{U}-\mathrm{N}_{2}\right)$ by $0.17 \AA$ in going from $U(V I)$ to $U(V)$. This peculiar behavior of $3^{\mathrm{V} / \mathbf{3}^{\mathrm{VI}}}$ system is because that the ethylene moieties between $\mathrm{N}_{1}$ and $\mathrm{N}_{2}$ are rather flexible, while the moieties consisting of $\mathrm{O}_{\mathrm{eq}}, \mathrm{C}_{1}, \mathrm{C}_{6}, \mathrm{C}_{8}$ and $\mathrm{N}_{1}$ in the
Table 1. Structural Parameters from EXAFS Curve Fits for U(V) and $\mathrm{U}(\mathrm{VI})$ Complexes in DMSO

\begin{tabular}{|c|c|c|c|c|c|c|c|}
\hline \multirow[b]{2}{*}{ shell $^{a}$} & \multicolumn{3}{|c|}{$\mathrm{U}(\mathrm{V})$} & \multicolumn{3}{|c|}{$\mathrm{U}(\mathrm{VI})$} & \multirow{2}{*}{$\begin{array}{l}R_{\text {cryst }} \\
/ \AA \AA\end{array}$} \\
\hline & $N$ & $R / \AA$ & $\sigma^{2} / \AA^{2}$ & $N$ & $R / \AA ̊$ & $\sigma^{2} / \AA^{2}$ & \\
\hline $1^{\mathrm{V} / 1^{\mathrm{VI}}}$ & \multicolumn{3}{|c|}{$\Delta E_{0}=7.1 \mathrm{eV}$} & \multicolumn{3}{|c|}{$\Delta E_{0}=6.1 \mathrm{eV}$} & \\
\hline $\mathrm{O}_{\mathrm{ax}}$ & $2^{b}$ & 1.84 & 0.0040 & $2^{b}$ & 1.80 & 0.0017 & 1.78 \\
\hline $\mathrm{O}_{\mathrm{eq}}$ & 2.2 & 2.29 & 0.0079 & 2.1 & 2.25 & 0.0025 & 2.27 \\
\hline $\mathrm{O}_{\text {DMSO }}$ & 1.1 & 2.91 & 0.0048 & 1.1 & 2.38 & 0.0020 & 2.41 \\
\hline $\mathrm{N}_{\mathrm{eq}}$ & 2.0 & 2.62 & 0.0098 & 2.1 & 2.56 & 0.0029 & 2.55 \\
\hline $\mathrm{C}_{\mathrm{O}}$ & 2.4 & 3.22 & 0.0100 & 2.0 & 3.23 & 0.0054 & 3.27 \\
\hline $\mathrm{C}_{\mathrm{N}}$ & 3.9 & 3.52 & 0.0094 & 4.0 & 3.44 & 0.0054 & 3.44 \\
\hline $\mathrm{S}$ & 1.1 & 3.71 & 0.0067 & 1.1 & 3.64 & 0.0019 & 3.61 \\
\hline $\mathrm{C}_{\mathrm{B}}$ & 2.4 & 3.80 & 0.0044 & 2.0 & 3.71 & 0.0044 & 3.74 \\
\hline $\mathrm{O}_{\mathrm{ax}}(\mathrm{MS})$ & $2^{b}$ & 3.69 & 0.0047 & $2^{b}$ & 3.60 & 0.0033 & - \\
\hline $2^{-V / 2}$ & \multicolumn{3}{|c|}{$\Delta E_{0}=9.8 \mathrm{eV}$} & \multicolumn{3}{|c|}{$\Delta E_{0}=5.4 \mathrm{eV}$} & \\
\hline $\mathrm{O}_{\mathrm{ax}}$ & $2^{b}$ & 1.85 & 0.0043 & $2^{b}$ & 1.78 & 0.0017 & 1.77 \\
\hline $\mathrm{O}_{\mathrm{eq}}$ & 3.9 & 2.49 & 0.0107 & 4.2 & 2.35 & 0.0043 & 2.33 \\
\hline $\mathrm{O}_{\text {DMSO }}$ & 1.0 & 2.89 & 0.0057 & 1.1 & 2.48 & 0.0033 & 2.46 \\
\hline $\mathrm{C}_{\mathrm{O}}$ & 4.2 & 3.54 & 0.0100 & 4.5 & 3.50 & 0.0145 & 3.38 \\
\hline $\mathrm{S}$ & 1.0 & 3.67 & 0.0040 & 1.1 & 3.57 & 0.0070 & $-^{c}$ \\
\hline $\mathrm{C}_{\mathrm{B}}$ & 2.0 & 3.73 & 0.0040 & 2.8 & 3.69 & 0.0087 & 3.79 \\
\hline $\mathrm{O}_{\mathrm{ax}}(\mathrm{MS})$ & $2^{b}$ & 3.70 & 0.0120 & $2^{b}$ & 3.57 & 0.0030 & - \\
\hline $\mathbf{3}^{\mathrm{V}} / \mathbf{3}^{\mathrm{VI}}$ & \multicolumn{3}{|c|}{$\Delta E_{0}=-4.5 \mathrm{eV}$} & \multicolumn{3}{|c|}{$\Delta E_{0}=-2.0 \mathrm{eV}$} & \\
\hline $\mathrm{O}_{\mathrm{ax}}$ & 1.7 & 1.86 & 0.0015 & $2^{b}$ & 1.81 & 0.0025 & 1.79 \\
\hline $\mathrm{O}_{\mathrm{eq}}$ & 1.7 & 2.27 & 0.0032 & 2.1 & 2.26 & 0.0018 & 2.23 \\
\hline $\mathrm{N}_{2}$ & 1.0 & 2.41 & 0.0008 & 30 & 259 & 00055 & 259 \\
\hline $\mathrm{N}_{1}$ & 1.7 & 2.60 & 0.0042 & 3.0 & & 0.0053 & \\
\hline $\mathrm{C}_{1}$ & 2.0 & 3.22 & 0.0163 & 2.0 & 3.12 & 0.0130 & 3.32 \\
\hline $\mathrm{C}_{9}$ & 4.0 & 3.49 & 0.0032 & 6.0 & 3.54 & 0.0065 & 3.48 \\
\hline $\mathrm{C}_{8}$ & 2.2 & 3.62 & 0.0011 & & & & \\
\hline $\mathrm{O}_{\mathrm{ax}}(\mathrm{MS})$ & 1.7 & 3.73 & 0.0024 & $2^{b}$ & 3.62 & 0.0069 & - \\
\hline $\mathrm{C}_{6}$ & 2.1 & 3.76 & 0.0046 & - & - & - & 3.84 \\
\hline
\end{tabular}

$\sigma^{2}$ : Debye-Waller factor, $\Delta E_{0}$ : Threshold energy shift. ${ }^{a}$ Atomic notation follows Chart $1 .{ }^{b}$ Fixed parameter. ${ }^{c}$ Not available because the model structure is $\mathrm{U}^{\mathrm{VI}} \mathrm{O}_{2}(\mathrm{dbm})_{2}$ (ethanol) in Ref. 13.

6-membered chelating rings are predicted to be rigid because of the conjugated $\pi$-electron system.

In a bare $\mathrm{UO}_{2}^{+}, \mathrm{U} 5 \mathrm{f} \delta$ and $5 \mathrm{f} \phi$ orbitals do not participate in any bond formation, but stay as degenerated non-bonding orbitals. ${ }^{15)}$ When an equatorial coordination forms, $5 \mathrm{f} \phi$ with 6 lobes localized on the $x y$ plane is involved in the interaction with ligands, having an anti-bonding character. In contrast, $5 \mathrm{f} \delta$ is still non-bonding, because its lobes are not present directly along any bonds. As a result, the unpaired electron in $\mathrm{U}^{5+}$ will occupy the non-bonding $5 \mathrm{f} \delta$ in the actual $\mathrm{U}(\mathrm{V})$ complexes. This configuration is energetically favorable from a viewpoint of electric repulsion, which is minimized at the ground state. Consequently, the unpaired U $5 f$ electron in U(V) does not participate in any chemical bond, while the decrease in effective charge of $U$ slightly lengthen both the axial and equatorial bonds in U(V) compared to those in U(VI). The expansion of the equatorial coordination sphere of $U(V)$ is suppressed in $3^{V}$ due to the stronger complexation ability of saldien ${ }^{2-}$. The unique flexibility of the coordination at the fifth equatorial site in the $\mathrm{U}(\mathrm{V})$ complexes, $\mathrm{U}-\mathrm{O}_{\mathrm{DMSO}}$ and $\mathrm{U}-\mathrm{N}_{2}$, is still an open question. 


\section{REFERENCES}

(1) Katz, J. J.; Seaborg, G. T.; Morss, L. R. The Chemistry of the Actinide Elements 2nd Edition, Chapman and Hall, London, New York, 1986.

(2) (a) Cohen, D. J. Inorg. Nucl. Chem. 1970, 32, 3525-3530. (b) Ferri, D.; Grenthe, I.; Salvotore, F. Inorg. Chem. 1983, 22, 3162-3165. (c) Madic, C.; Hobart, D. E.; Begun, G. M. Inorg. Chem. 1983, 22, 1494-1503. (d) Mizuguchi, K.; Park, Y.-Y.; Tomiyasu, H.; Ikeda, Y. J. Nucl. Sci. Technol. 1993, 30, 542-548. (e) Mizuoka, K.; Grenthe, I.; Ikeda, Y. Inorg. Chem. 2005, 44, 4472-4474. (f) Docrat, T. I.; Mosselmans, J. F. W.; Charnock, J. M.; Whiteley, M. W.; Collison, D.; Livens, F. R.; Jones, C.; Edmiston, M. J. Inorg. Chem. 1999, 38, 1879-1882. (g) Ikeda, A.; Hennig, C.; Tsushima, S.; Takao, K.; Ikeda, Y.; Scheinost, A. C.; Bernhard, G. Inorg. Chem. 2007, 46, 4212-4219.

(3) (a) Adams, M. D.; Wenz, D. A.; Steunenberg, R. K. J. Phys. Chem. 1963, 67, 1939-1941. (b) Wenz, D. A.; Adams, M. D.; Steunenberg, R. K. Inorg. Chem. 1964, 3, 989-992.

(4) (a) Mizuoka, K.; Kim, S.-Y.; Hasegawa, M.; Hoshi, T.; Uchiyama, G.; Ikeda, Y. Inorg. Chem. 2003, 42, 1031-1038. (b) Mizuoka, K.; Ikeda, Y. Inorg. Chem. 2003, 42, 3396-3398. (c) Mizuoka, K.; Ikeda, Y. Radiochim. Acta 2004, 92, 631-635. (d) Mizuoka, K.; Tsushima, S.; Hasegawa, M.; Hoshi, T.; Ikeda, Y. Inorg. Chem. 2005, 44, 6211-6218. (e) Berthet, J.-C.; Nierlich, M.; Ephritikhine, M. Angew. Chem. Int. Ed. 2003, 42, 1952-1954. (f) Berthet, J.-C.; Siffredi, G.; Thuery, P.; Ephritikhine, M. Chem. Commun. 2006, 3184-3186, (g) Natrajan, L.; Burdet, F.; Pecaut, J.; Mazzanti, M. J. Am. Chem. Soc. 2006, 128, 7152-7153. (h) Burdet, F.; Pecaut, J.; Mazzanti, M. J. Am. Chem. Soc. 2006, 128, 16512-16513. (i) Nocton, G.; Horeglad, P.; Pecaut, J.; Mazzanti, M. J. Am. Chem. Soc. 2008, 130, 16633-16645. (j) Hayton, T. W.; Wu, G. Inorg. Chem. 2008, 47, 7415-7423. (k) Hayton, T. W.; Wu, G. J. Am. Chem. Soc. 2008, 130, 2005-2014. (1) Hayton, T. W.; Wu, G. Inorg. Chem. 2009, 48, 3065-3072. (m) Horeglad, P.; Nocton, G.; Filinchuk, Y.; Pecaut, J.; Mazzanti, M. Chem. Commun. 2009, 1843-1845. (n) Arnold, P. L.; Patel, D.; Wilson, C.; Love, J. B. Nature, 2008, 451, 315-317.

(5) Takao, K. Kato, M.; Takao, S.; Nagasawa, A.;
Scheinost, A. C.; Bernhard, G.; Hennig, C.; Ikeda, Y. Actinides 2009 International Conference, 3P8, San Francisco, USA, 2009. IOP Conference Series: Materials Science and Engineering, to be submitted. CIF of $3^{\text {VI }}$.DMSO (CCDC 739692) is available free of charge via www.ccdc.cam.ac.uk/data_request/cif.

(6) Takao, K.; Ikeda, Y. Inorg. Chem. 2007, 46, 1550-1562.

(7) Reich, T.; Bernhard, G.; Geipel, G.; Funke, H.; Hennig, C.; Rossberg, A.; Matz, W.; Schell, N.; Nische, H. Radiochim. Acta 2000, 88, 633-637.

(8) Ressler, T. J. Synchrotoron Rad. 1998, 5, 118-122.

(9) Ravel, B.; Newville, M. J. Synchrotoron Rad. 2005, 12, 537-541.

(10) Ankudinov, A. L.; Ravel, B.; Rehr, J. J.; Conradson, S. D. Phys. Rev. B 1998, 58, 7565-7576.

(11) (a) Templeton, D. H.; Templeton, L. K. Acta Crystallogr. 1982, A38, 62-67. (b) Hudson, E. A.; Allen, P. G.; Terminello, L. J.; Denecke, M. A.; Reich, T. Phys. Rev. $B, 1996,54,156-165$.

(12) Hennig, C. Phys. Rev. B, 2007, 75, 035120.

(13) Takao, K.; Ikeda, Y. Acta Cryst. 2008, E64, m219-220.

(14) Bondi, A. J. Phys. Chem. 1964, 68, 441-451.

(15) Matsika, S.; Zhang, Z.; Brozell, S. R.; Blaudeau, J.-P.; Wang, Q.; Pitzer, R. M. J. Phys. Chem. A, 2001, 105, 3825-3828 